\title{
Besin Alımının Kontrolündeki Anoreksijenik Peptit: Nesfatin-1
}

\author{
Duygu GÖK YURTSEVEN ${ }^{1}$, Zehra MINBAY ${ }^{2}$, Özhan EYİGÖR ${ }^{2}$ \\ 1 SANKO Üniversitesi Tıp Fakültesi, Histoloji ve Embriyoloji Anabilim Dalı, Gaziantep. \\ 2 Uludağ Üniversitesi Tıp Fakültesi, Histoloji ve Embriyoloji Anabilim Dalı, Bursa.
}

\begin{abstract}
ÖZET
Enerji homeostazının regülasyonunda yer alan açlık ve tokluğun fizyolojik mekanizması, besin alımını uyarıcı oreksijenik faktörlerle inhibe edici anoreksijenik çoğu faktörün birleşiminden oluşan kompleks bir süreçle düzenlenir. Son on yılda, besin alımı ve enerji harcanmasını değiştiren pek çok nöropeptid tanımlanmıştır. NEFA/Nükleobindin2 prekürsöründen türeyen nesfatin-1 peptidi besin alımını baskılayan hipotalamik nöropeptid olarak karșımıza çıar. Nesfatin-1 ilk defa hipotalamus ve soliter traktusta (NTS) yerleşik nöronlarda belirlenmiștir. Nesfatin-1 nöronlarının beyin alanlarındaki ekspresyon profilleri, fizyolojik mekanizmalar üzerindeki etkisi ve de diğer nöropeptidlerle olan kolokalizasyonları hala üzerinde çalışılmakta olan konulardandır. Laboratuvarımızda yürütülen çalışmalarda bizde nesfatin-1'in hipotalamik çekirdeklerdeki lokalizasyonunu belirledik. Bu derlemede, nesfatin nöronlarının lokalizasyonunun yanı sıra, nesfatin-1 peptidinin fizyolojisi ile fonksiyonlarına ait, bugüne kadar literatürde yer alan bilgilere yer verilmiştir.
\end{abstract}

Anahtar Kelimeler: NUCB2. Nesfatin-1. Hipotalamik çekirdekler. Beslenme.

Anorexigenic Peptide in the Control of Food Intake: Nesfatin-1

\begin{abstract}
The sensations of hunger and fullness during the regulation of the energy homeostasis are regulated through a complex process. This process consists of many anorexigenic factors' combination that inhibit food intake as well as appetite-stimulating (orexigenic) factor. In the last decade, many neuropeptides have been identified that alter food intake and energy expenditure. Nesfatin-1 peptide derived from the NEFA/nucleobindin2 precursor have emerged as a hypothalamic neuropeptide suppressing the food intake. Nesfatin-1 was first identified in the hypothalamus and solitary tract neurons (NTS). The expression profiles in the brain areas of NUCB2/nesfatin-1 neurons, their effect on physiological mechanisms, and their co-localizations with other neuropeptides are topics still studied. In the studies carried out in our laboratory, we also have identified the location of nesfatin-1 in the hypothalamic nuclei. In this review, in addition to the localization of nesfatin neurons, recent literature knowledge on the physiology and functions of nesfatin-1 peptide are included.
\end{abstract}

Key Words: NUCB2. Nesfatin-1. Hypothalamic nuclei. Feeding.

Nesfatin-1 ilk kez Oh-I ve arkadaşları tarafından 2006 yılında keşfedilmiş, 82 aminoasite sahip endojen bir protein olarak tanımlanmış, homeostatik beslenmenin kontrolünde rol oynayan anoreksijenik bir peptidtir. Etkileri dolayısıyla "tokluk molekülü" olarak da adlandırılan nesfatin-1, ilk defa hipotalamus ve soliter traktusta (NTS) yerleşik nöronlarda belirlenmiştir ${ }^{1}$. Nesfatin'in, periferik ya da merkezi yolla deneklere uygulandığında besin alımının baskılandığ ${ }^{2-5}$ ve dola-

Geliş Tarihi: 24 Temmuz 2018

Kabul Tarihi: 04 Ağustos 2018

Dr. Özhan EYIGÖR

Uludağ Üniversitesi Tıp Fakültesi,

Histoloji ve Embriyoloji Anabilim Dalı, Bursa.

Tel.: 05335177809

E-posta: oeyigor@uludag.edu.tr yısıyla vücut ağırlık kaybına yol açtığının gösterilmesiyle birlikte, bu peptidin iştahı kontrol eden yolaktaki önemi ortaya çıkmıştır. Leptin geni susturulmuş (knockdown fareler) obez farelerde bile besin alımının nesfatin-1 peptidi tarafından baskılandığının ortaya çıkarılması bu peptidin hem leptin yolağından bağımsız bir şekilde çalıştığını hem de leptin geninde mutasyon olan obez bireylerin tedavi sürecinde araştırılması gereken bir molekül olduğunu düşündürmektedir.

\section{Nesfatin-1 Geninin Keşfi ve Moleküler Yapısı:}

Nesfatin-1'in keşfi, adipositler ile medulloblastoma hücrelerinde ifade edilen nükleobindin (NUCB) veya NEFA (DNA bağlayıcı /EF-hand/ asidik aminoasit açısından zengin bölge) geninin tanımlanması ile başlamıştır. Bu gen, peroksizom-proliferatörü ile aktive olan reseptör geni PPAR $\gamma$ 'nın uyarılmasıyla aktive 
edilen troglitazone'un ligandı olarak rol oynamakta$\mathrm{d}^{6} \mathrm{r}^{6}$. Şimdiye kadar nükleobindin1 (NUCB1) ve nükleobindin2 (NUCB2 veya NEFA) olmak üzere 2 tane nükleobindin geni tanımlanmıştır?

Rekombinant nükleobindin2 (NUCB2) proteininin beyine enjekte edildiğinde, besin alımını azalttığının ve vücut ağırlığının kontrolünde yer alan hipotalamik çekirdeklerde ifade edildiğinin gösterilmesinin ardından bu faktör nesfatin (NEFA/NUCB2 ile kodlanmış tokluk ve yağ-etkili protein) olarak isimlendirilmiştir ${ }^{1}$. NUCB2/nesfatin, 396 aminoasit (aa) içeren polipeptidli bir yapı ile 24 aminoasitin oluşturduğu Nterminal sinyal peptidinden meydana gelir ${ }^{8}$ (Şekil 1). Yapısal analizler sonucunda siçanlardaki NUCB2/ nesfatin dizilerinin (sekans) prohormon konvertaz (PC-1/3) enzimleriyle post-translasyonel bir şekilde bölünmesi sağlanarak nesfatin-1 (1-82 aa), nesfatin-2 (85-163) ve nesfatin-3 (166-396 aa) prokürsörleri tanımlanmıştır. NUCB2'nin sinyal peptidinin hemen ardında yer alan nesfatin-1 (1-82 aa), N-terminal (N23), merkezi parça (M30) ve C-terminal (C29) olmak üzere 3 alt bölümden oluşmaktadır. M30 orta parçası, bu peptidin fizyolojik süreçlerde özellikle de anorektik cevapta etkin bir şekilde rol almasını sağlayan aktif kısmını oluştururken, nesfatin-2 (85-163 aa) ve nesfatin-3 (166-396 aa) tokluk hissini uyarmayan uzun sekanslı inaktif formlarıdır ${ }^{1,5,9}$ (Şekil 1).

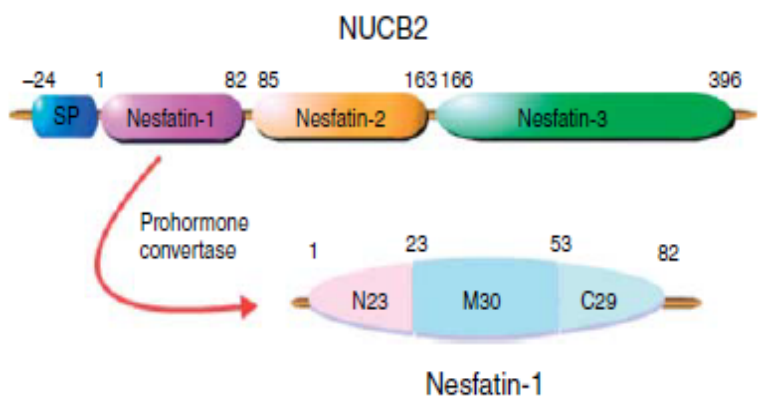

Sekil 1.

NUCB2 proteini, nesfatin-1 (1-82 aa) ve nesfatin-1'in üç farkl parçasının (fragman) aminoasit dizisi görülmektedir ${ }^{9}$. SP: sinyal peptidi.

\section{Nesfatin-1'in Sinyal İletimi:}

NUCB2/nesfatin-1 reseptörü henüz belirlenememiş olmasına rağmen nesfatin-1'in spesifik bağlanma alanları hem merkezi sinir sisteminde (hipotalamus ve beyin korteksi) hem de periferal organlarda (gastrointestinal sistem, hipofiz, ve pankreas gibi) gösterilmiş$\operatorname{tir}^{10,11}$.

Nesfatin-1'in hedef hücrelerin nöroplazmasındaki $\mathrm{Ca}^{2+}$ iyon konsantrasyonunu arttırdığına dair pek çok veri bulunmaktadır ${ }^{5}$. Çoğu hücre tipinde (hipotalamik çekirdekler, dorsak kök gangliyonu (DRG) nöronları, pankreatik $\beta$-hücreleri ve kardiak miyositler gibi) ${ }^{12}$ nesfatin-1'in hücre içi sinyal iletimini, $\mathrm{L}^{-13}$, P/Q- ${ }^{14,15}$ veya $\mathrm{N}^{-16}$ tipi $\mathrm{Ca}^{2+}$ kanalları vasitasıyla $\mathrm{Ca}^{2+}$ akımını uyararak yaptığı bildirilmiştir. Gi-protein-bağlı reseptörün nesfatin-1 ile uyarılması, $\mathrm{Ca}^{2+}$ kanallarının açılmasına ve/veya hipotalamik nöronlarda protein kinaz A ve adenilat siklaz yolağının aktive edilmesine yol açar. Nesfatin-1'in metabotropik reseptörler üzerinden ligand olarak rol oynamasıyla sinyal iletimi gerçekleştirilmiş olur ${ }^{5,14}$.

\section{NUCB2/Nesfatin-1'in İfadesi:}

\section{a. Nesfatin-1'in Hücresel Düzeyde İfadesi}

Nesfatin-1'in lokalizasyonuna hücresel düzeyde bakıldığında, hipotalamik PVN çekirdekteki nesfatin-1pozitif nöronların Golgi aparatı yanındaki salgılayıcı veziküllerde yer aldığ 1 , akson terminallerinde bulunmadığı rapor edilmiştir. Ayrıca nesfatin-1'in nöronal dentritlerden salındığı dolayısıyla da otokrin ve parakrin olayların sonucunda bu alanda lokalize olduğu bildirilmiştir ${ }^{17}$.

\section{b. Nesfatin-1'in Merkezi İfadesi}

Siçanlar üzerinde gerçekleştirilen ilk immünohistokimyasal çalışmalar NUCB2 proteininin, beslenmenin merkezi düzenlenmesinde rol alan hipotalamik çekirdeklerden arkuat çekirdek (ARC), paraventriküler çekirdek (PVN), supraoptik çekirdek (SON) ve lateral hipotalamik alanda (LHA) lokalize olduğunu göstermiştir ${ }^{1}$.

Siçan, fare ve domuzlar üzerinde yapılan sonraki çalışmalar diğer beyin bölgeleri ile hipotalamik çekirdeklerde [insular korteks, merkezi amigdaloid çekirdek, periventriküler çekirdek (PVN), tuberal hipotalamik alan (THA), dorsomedial hipotalamik çekirdek (DMN), Edinger-Westphal (EW) çekirdeği, medullar raphe çekirdeği, kaudal raphe çekirdeği, ventrolateral medulla (VLM), lokus koeruleus (LC), serebellum, vagusun dorsal motor çekirdeği (DMV), soliter traktus (NTS) ve spinal kord'un pregangliyonik sempatik ve parasempatik nöron gruplarında] NUCB2/nesfatin-1 lokalizasyonunu göstermiştir ${ }^{18-23}$. Bu lokalizasyon sonuçları, Nucb2/nesfatin-1 mRNA's1 ve immünoreaktivitesini araştıran çoğu araştırmacı tarafından doğrulanmıştıı ${ }^{14,18,20,23,24}$. Biz de laboratuvarımızda gerçekleştirdiğimiz çalışmalarda nesfatin-1'i içeren nöronların lokalizasyonunun literatürle uyumlu olduğunu belirledik (Şekil 2).

NUCB2/nesfatin-1'in beyindeki bu yaygın dağılımı, nesfatin-1'in besin alımı üzerindeki etkisinin de ötesinde olan fonksiyonlarda (otonomik işlevler ve strese yanıt) rol aldığını düşündürmektedir ${ }^{6}$. Ayrıca farelerde NUCB2/nesfatin-1 immünreaktivitesinin hipotalamusun intermediate dorsomedial alanında belirgin bir şekilde gösterilmesi yeni hipotalamik çekirdeklerin tanımlanması açısından önemlidir ${ }^{24}$. 

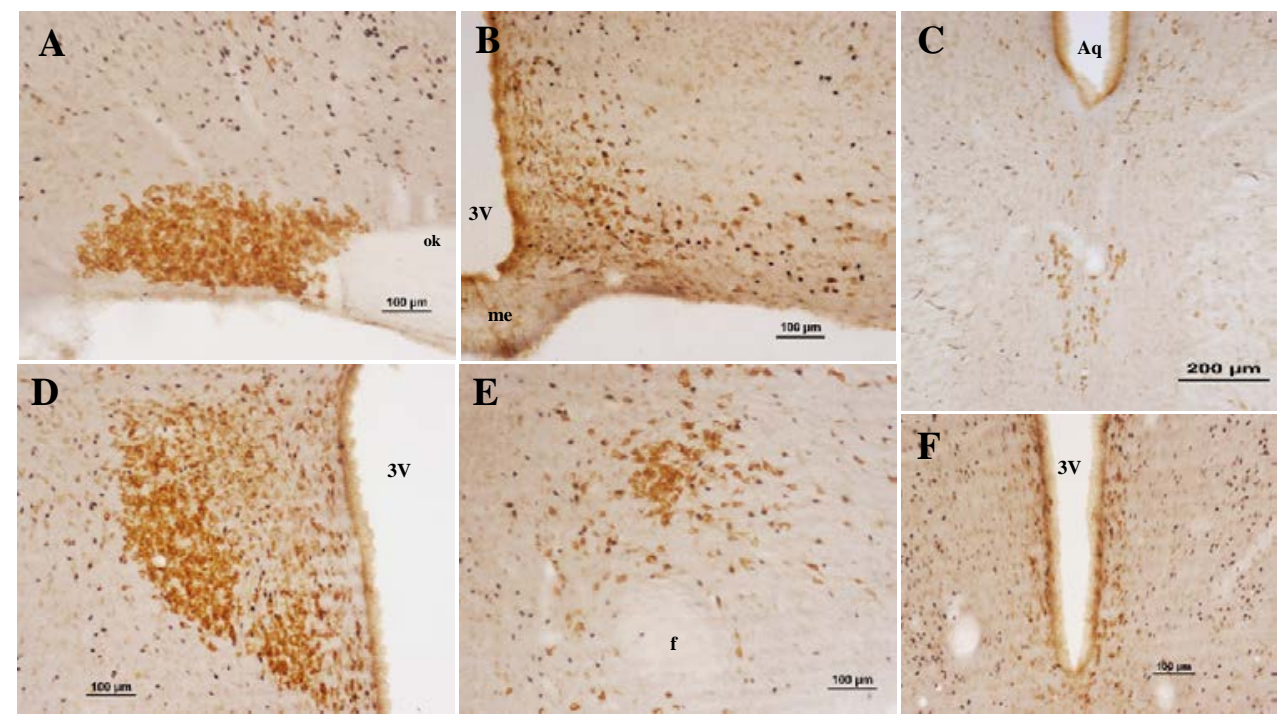

Shekil 2.

Nesfatin-1-pozitif nöronların diş̧ sı̧̧an hipotalamik çekirdeklerdeki dăğllmı. (A) Supraoptik çekirdek (SON),

(B) Arkuat çekirdek (ARC), (C) Edinger-Westphal çekirdek (EW), (D) Paraventriküler çekirdek (PVN), (E)

Lateral hipotalamik alan (LHA) ile (F) Periventriküler çekirdekte (PeV) lokalize nesfatin-1 immünreaktivitesi gösteren nöronlar ayırt edilmektedir. 3V: üçüncü ventrikül, ok: optik kiazma, me: median eminens, Aq: Aqueduct, f: forniks.

İkili immünohistokimya yöntemi kullanılarak yapılan çalışmalarda NUCB2/nesfatin-1'in lokalizasyonunun yanısıra bu peptidi ifade eden nöronların fenotipi de araştırılmıştır ${ }^{6}$. Nesfatin-1'i içeren nöronlar, açlık ve tokluğun regülasyonunda yer alan diğer nöropeptidlerle ko-lokalize olarak bulunabilirler.

NUCB2/nesfatin-1'in; ürokortin-1 (\% 90), melaninkonsantre edici hormon (MCH, \% 80), kokain ve amfetamin-düzenleyici transkript (CART, \% 70), $\alpha$ melanosit-uyarıcı hormon ( $\alpha$-MSH, \% 60), proopiomelanokortin (POMC, \% 60-80), vazopressin (\% 50), nöropeptid Y (NPY, \% 40), oksitosin (\% 40), büyüme hormonu-saliveren hormon (GHRH, \% 30), kortikotropin-salıveren faktör (CRF, \% 20), tirotropin salıveren hormon (TRH, \% 20), somatostatin (\% 10), nörotensin (\% 10) ve serotonin nöropeptidleriyle ko-lokalize olduğu gösterilmiştir ${ }^{22,23,25,26}$.

\section{c. Nesfatin-1'in Periferal Dokulardaki İfadesi}

NUCB2/nesfatin-1'in beyindeki lokalizasyonunun yanı sıra, çoğu periferal dokudaki ifadesi çeşitli çalışmalarda ortaya konmuştur. Sıçanların ve kırmızı balıkların (goldfish) ön hipofiz bezi, yağ dokusu, kalp, pankreas, mide ve testis dokularında nesfatin-1 peptidinin ekspresyonları gösterilmiştir ${ }^{27-32}$. Ayrıca midedeki Nucb2 mRNA ifade düzeyinin, sıçan beynindeki ifade düzeyinden 10 kat daha fazla olduğu bildirilmiştir. Midedeki NUCB2/nesfatin-1'i ifade eden hücrelerin hem gastrik endokrin hücrelerdeki dominant varlı$\breve{g} 1$ hem de gastrik X-A benzeri hücrelerdeki varlığ gösterilmiştir ${ }^{32}$.
Pankreasta ise NUCB2/nesfatin-1'in Langerhans adacığının $\beta$-hücrelerinden salgılanan insülin ile kolokalize olduğu bildirilmiştir ${ }^{28}$. NUCB2/nesfatin-1 peptidinin yaygın periferal dağılımı, aslında homeostatik yolakta yer alan çoğu peptidle olan ilişkisini ortaya koymaktadır.

\section{Besin Alımında Nesfatin-1’in Etkileri:}

\section{a. Merkezi Etkileri}

Wistar cinsi erkek sıçanlarda yapılan doz bağımlı çalışmalarda, bu molekülün üçüncü beyin ventrikülüne intraserebroventriküler (i.c.v.) enjeksiyonu ile yiyecek alımının ve vücut ağırlığının azaldığı gösterilmiştir $^{1}$. Bu sonuç, birbirinden bağımsız olarak çalışan çoğu araştırmacı tarafindan doğrulanmıştır. Fareler 33,34, sıçanlar ${ }^{35-37}$ ve kırmızı balıklar (goldfish) ${ }^{38}$ üzerinde yapılan çoğu araştırmada nesfatin-1'in lateral, üçüncü, dördüncü beyin ventriküllerine, sisterna magna'ya, hipotalamik çekirdeklerden PVN, LHA ve dorsal vagal komplekse (DVC) yapılan düşük dozdaki (5-20 pmol) i.c.v. enjeksiyonlarının sonucunda anoreksijenik etkilerinin olduğu bildirilmiştir ${ }^{6,39}$.

$\mathrm{Bu}$ bulguların ardından gelen araştırmalar nesfatin1 'in anoreksijenik etkilerinin kinetiğini karakterize etmeye çalışmıştır. Siçanlarda lateral beyin ventrikülüne yapılan düşük dozdaki (5 pmol) enjeksiyonun sonucunda nesfatin-1'in karanlık evrede ve uzun süreli (6-48 saat süren) şekilde besin alımını azalttığı gösterilmiştir ${ }^{39-41}$. Siçanlara yüksek dozdaki (25-80 pmol) nesfatin-1'in i.c.v. enjeksiyonu sonrası anoreksijenik etki yanında anksiyete benzeri davranışların da arttığı 
gözlenmiştir ${ }^{42}$. İlginç bir şekilde, üçüncü, dördüncü beyin ventrikülleri ya da sisterna magna'ya yapılan enjeksiyonlarda, nesfatin-1'in anoreksijenik etkisinin post-enjeksiyonun ilk birinci saatinde ortaya çıktığ 1 , arka beyin bölgelerine karşıllk ön beyin bölgelerinde bu etkinin farklı düzeylerde olduğu gözlenmiştir ${ }^{1,41}$.

Beyin parankimasına mikroenjeksiyon kullanılarak yapılan sonraki çalışmalarda nesfatin-1'e duyarlı hipotalamik beyin bölgeleri araştırılmıştır. Nesfatin-1'in direk olarak PVN'e ya da yüksek dozlarda LHA'a mikroenjeksiyonları karanlık evredeki besin alımını azaltırken, VMH'a olan mikroenjeksiyonları sonucunda herhangi bir etki gözlenmemiştir ${ }^{43}$. Bu sonuç, PVN'in nesfatin-1'in anoreksijenik etkisinde rol alan primer hipotalamik alan olduğu şeklinde yorumlanmıştır. Wistar cinsi erkek sıçanlar kullanılarak yapılan başka bir çalışmada, endojen beyin NUCB2/nesfatin-1 sinyalinin üçüncü beyin ventrikülü içine yapılan antinesfatin-1 antikoru ya da anti-NUCB2 antisense oligonükleoditinin enjeksiyonu ile bloke edilmesi sonucunda, hayvanlarda beslenmenin ve kilo alımının $\operatorname{arttığ1~gösterilmiştir~}^{44}$. SON ve PVN'deki Nucb2 mRNA'sı ve protein ifadesinin açlık durumlarında azaldığı, tekrar beslenmenin sağlanmasıyla nesfatin-1 seviyelerinin normale döndüğü gözlenmiştir ${ }^{23,45}$. Ayr1ca paraventriküler çekirdekteki Nucb2 mRNA düzeyleri, besin alımının minumum olduğu aydınlık evrede artarken besin alımlarının oldukça yüksek olduğu karanlık evre boyunca azalmıştır ${ }^{46}$.

\section{b. Periferal Etkileri}

Nesfatin-1'in besin alımını kontrol eden yolaktaki santral etkilerinin yanında periferal etkileri de son zamanlarda yoğun araştırma konusu olmuştur. $\mathrm{Bu}$ peptidin kemirgenlerin ${ }^{47}$ ve insanların ${ }^{48}$ plazmalarındaki varlığı gösterilmiş olmasına rağmen dolaşımdaki kaynağının ne olduğu hala bilinememektedir. Plazmadaki nesfatin-1'in olası kaynakları olarak subkutanöz yağ dokusu, gastrik mukozanın endokrin hücreleri ve bağırsaklar, endokrin pankreas, özellikle de pankreatik $\beta$-hücreleri gösterilmektedir ${ }^{29,31,49}$.

Açlıkta NUCB2/nesfatin-1'in dolaşımdaki miktarının giderek azaldığı, tekrar beslenmenin sağlanmasıyla nesfatin-1 seviyesinin normale döndüğü bildirilmiş$\operatorname{tir}^{41}$. Benzer şekilde sıçanlara nesfatin-1'in devamlı periferal infüzyonu, kümülatif besin alımını azaltmış$\mathrm{tir}^{50}$.

Farelere intraperitoneal (i.p.) olarak verilen yüksek dozdaki nesfatin-1'in karanlık evredeki besin alımını azaltarak beslenmeyi etkilediği bildirilmiştir ${ }^{8}$. Yüksek yağ içerikli diyetle beslenmiş obez farelerde veya leptin reseptör geninde mutasyon içeren $\mathrm{db} / \mathrm{db}$ farelerde, beslenmeyi engelleyici etkinin devam ettiği gösterilerek bu etkinin leptin sinyalinden bağımsız bir şekilde olduğu bildirilmiştir ${ }^{1,8}$. Yapısal olarak birbirinden farklı olan nesfatin-1 fragmanları (N-terminal, Cterminal ya da orta parça) kullanılarak yapılan bir araştırmada karanlık fotoperiyotta besin alımını baskılayan biyolojik aktivitenin nesfatin-1'in orta parçasından (24-53 aa) kaynaklandığı, diğer N- ve C- terminal fragmanların i.p. enjeksiyonları sonrası besin alımında herhangi bir etkinin olmadığı gösterilmiştir ${ }^{8}$.

Nesfatin-1'in periferik uygulanması sonrasında kanbeyin bariyerini geçtiği, dolaşımdaki nesfatin-1'in plazmadan parankim içine doğru olan difüzyonu sonrasında beyindeki beslenme merkezlerini doğrudan etkileyebildiğinden söz edilmektedir ${ }^{51,52}$. Fakat İn vitro ortamda nesfatin-1'in nodoz gangliyon nöronlarını aktive ettiğinin gösterilmesinin ardından, nesfatin1 'in indirekt mekanizmasının olduğu da bildirilmiştir. Nesfatin-1'in indirekt etkisini, vagal afferentlerin aktivitesini etkileyerek ya da soliter traktusdaki POMC ve CART nöronlarını aktive ederek yaptığından bahsedilmektedir ${ }^{8,16}$. Bu sonuçlar aslında endojen nesfatin-1'in anoreksijenik düzenlenmeye aracılık ettiğini göstermektedir.

\section{Nesfatin-1'in Beslenmeyi Düzenleyici Sistemlerle Olan İlişkisi:}

Nesfatinerjik sistemin, beslenme davranışını düzenlediği bilinen diğer sistemlerle etkileşim içinde olduğu gösterilmiştir. Anoreksijenik peptid $\alpha$-MSH'ın enjeksiyonu, hem PVN'deki NUCB2/nesfatin-1 nöronlarını hem de Nucb2 mRNA ifadesini arttırmıştır. Buna karşılık nesfatin-1 tarafından indüklenmiş anoreksijenik etki, MC3/4 reseptör antagonisti (SHU9119)'nin merkezi olarak verilmesiyle durdurulmuştur ${ }^{53}$. Nesfatin-1'in merkezi ya da periferal olarak verilmesi, soliter traktus çekirdeğindeki (NTS) POMC/CART fenotipine sahip nöronların mRNA ifadelerini arttırırken hipotalamik seviyedeki (PVN ve ARC'de) nöronların mRNA ifadesini değiştirmemiştir ${ }^{1,8,54}$.

Nesfatin-1'in anoreksijenik etkisine, oksitosinerjik nöronların kısmen aracılık ettiği bildirilmiştir. Supraoptik ve paraventriküler çekirdekte yer alan magnoselüler nöroendokrin nöronlarda, oksitosinle nesfatin1 'in ko-lokalize olduğu gösterilmiştir ${ }^{18,23}$. İ vitro çalışmalarda, PVN'deki oksitosinerjik nöronların eksitabilitesinin (uyarılabilme özelliği) nesfatin-1 peptidi tarafından sağlandığ ${ }^{55}$, endojen nesfatin-1'in ise PVN dilimlerinde oksitosin salınımını değiştirdiği gösterilmiştir ${ }^{44}$. Paraventriküler çekirdeğe nesfatin1 'in enjeksiyonu, hem soliter traktusdaki c-fos ifadesini arttırmıs hem de oksitosin sisteminin uyarılmasıyla beslenmeyi baskılamıştır. Bu sonuç, paraventriküler çekirdekten soliter traktusa doğru uzantılarını gönderen oksitosinerjik nöronların, anoreksiyi indükleyen nesfatin-1 tarafından modüle edildiğini düşündürmektedir $^{44}$.

Nesfatinerjik sistemin, beslenme davranışını düzenleyen $\mathrm{CRF} / \mathrm{CRF}_{2}$ reseptör sistemiyle de etkileşim halinde olduğu bulunmuştur. Parvoselüler nöroendokrin nöronlarda CRF ile nesfatin-1'in ko-lokalizasyonu gösterilmiştir ${ }^{18,23}$. İn vitro da, nesfatin-1'in CRF pro- 


\section{Anoreksijenik Peptit: Nesfatin-1}

tein düzeylerini arttırdığı, CRF-eksprese eden nöronların eksitabilitesini etkilediği gösterilmiştir ${ }^{56,57}$. Ön beyine $\mathrm{CRF}_{2}$ reseptör antagonistinin (astressin ${ }_{2}-\mathrm{B}$ ) uygulanması ile nesfatin-1'in anoreksijenik etkisi tamamen ortadan kaldırılmıştır ${ }^{41}$.

NUCB2/nesfatin-1'in arkuat çekirdekteki NPY ile kolokalize olduğunun gösterilmesinin ${ }^{1,14}$ ardından in vitro da NPY-ifade eden nöronların çoğunluğunun nesfatin-1 ile hiperpolarize olduğu bulunmuştur ${ }^{56}$. Nesfatin-1'in NPY sinyalini negatif yönde etkileyerek besin alımını baskıladığı düşünülmüştür. Nesfatin-1'in sıçanlara i.c.v. enjeksiyonu, hipotalamus ve soliter traktusdaki NPY mRNA ifadesini azaltmıştır ${ }^{54}$.

Ayrıca, NUCB2/nesfatin-1'in besin alımını düzenleyen diğer nörotransmitterler ve hormonal peptidlerle olan ilişkisi, immünohistokimyasal çalışmalarla da gösterilmiştir. Paraventriküler ve supraoptik çekirdekte yer alan magnoselüler nöroendokrin nöronlarda, vazopressin ve oksitosin ile nesfatin-1'in ko-lokalize olduğu gösterilmiştir ${ }^{23}$. Benzer şekilde parvoselüler nöroendokrin nöronlarda büyüme hormonunu salgılayıc1 hormon (GHRH), nörotensin, somatostatin, kortikotropin salgilayıc1 hormon ve tirotropin salg1layıc1 hormon ile nesfatin-1'in ko-lokalizasyonu, arkuat nukleus da pro-opiomelanokortin (POMC) ile nesfatin-1'in ko-lokalizasyonu, lateral hipotalamus da melanin yoğunlaştırıcı hormon $(\mathrm{MCH})$ ile nesfatin-1'in ko-lokalizasyonları ikili immunohistokimya tekniği kullanılarak gösterilmiştir ${ }^{18}$. Açlık sonrası tekrar beslenen sıçanlarda, c-Fos immünreaktivitesinin nöronal aktivasyon belirteci olarak kullanıldığı bir çalışmada, paraventriküler ve supraoptik çekirdekte yerleşik nesfatin-1 nöronlarının aktive oldukları belirlenmiş$\operatorname{tir}^{23}$. Paraventriküler çekirdekte yerleşik nesfatin-1 nöronlarının, kolesistokinin enjeksiyonunu takiben cFos ifade ettikleri gösterilmiştir ${ }^{58}$. Stres uygulanan deneklerde nesfatin-1 nöronlarının büyük kısmının cFos ifade ettikleri görülmüştür ${ }^{59}$. Nesfatin-1 uygulanan nöronal hücre kültüründe CREB fosforilasyon düzeyinin arttığı yani nesfatin-1'in nöronal aktivasyona etki ettiği rapor edilmiştir ${ }^{10}$.

\section{Nesfatin-1'in Diğer Sistemlerle Olan İlişkisi:}

Nesfatin-1'in merkezi olarak (i.c.v.) uygulanmas1, nabzı ve arteriyel kan basıncını artırarak kardiyovasküler etkilere neden olmaktadır ${ }^{60,61}$. Nesfatin-1'in renin-anjiyotensin sistemini kullanarak kan basıncının düzenlenmesinde rol aldığı ayrıca renal sempatik sinir aktivitesini arttırdığ 1 gösterilmiştir ${ }^{62,63}$. Soliter traktus çekirdeğinin median kısmına nesfatin-1'in lokal enjeksiyonu da hem kan basıncinın hem de nabız sayıs1nın artmasina sebep olmaktadır ${ }^{64}$. Nesfatin-1'in anoreksijenik sinyalini ileten çoğu nöropeptidin, kardiyovasküler sistemin kontrolünde yer aldığı bilinmekte$\operatorname{dir}^{65}$. Özellikle melanokortin sisteminin aşırı derecede uyarılması çoğu hayvan modelinde hipertansiyona sebep olabilmektedir ${ }^{66}$. Nesfatin-1'in i.c.v. enjeksiyo- nu, önce POMC nöronlarını sonrasında oksitosin nöronlarını ardından da CRF nöronlarını ardışık bir şekilde aktive eder. Nöronların bu şekilde sıralı aktivasyonuyla kan basıncının artması sağlanır ${ }^{60,67}$.

Nesfatin-1'in, anksiyete, depresyon ve stres üzerinde de düzenleyici olarak rol oynadığı öne sürülmüştür. Anksiyete benzeri davranış ve stres cevabında rol aldığı bilinen beyin bölgelerinde (amigdaloid çekirdekler, stria terminalisin bed çekirdeği, paraventriküler çekirdek ve hipokampüs gibi) azımsanmayacak miktarlarda NUCB2/nesfatin-1 immünreaktivitesi tespit edilmiştir ${ }^{14,19,20,24}$. Hareketsizlik stresine maruz kalan sıçanların NUCB2/nesfatin-1 plazma düzeylerinde herhangi bir değişim gözlenmezken ${ }^{68}$, sudan kurtulma testinde bu seviyelerin arttığı görülmüştür ${ }^{69}$. Hareketsizlik stresine maruziyette hem kortikosteron serum seviyeleri ${ }^{70}$ hem de NUCB2/nesfatin-1 nöronlarındaki c-Fos ifadesi ${ }^{68}$ artmaktadır. İnsanlardan elde edilen son veriler, stresle-ilişkili duygu durum bozuklukları ile nesfatin-1 arasında bir ilişkinin olabileceği yönündedir. Majör depresif bozukluklardan etkilenen hastaların NUCB2/nesfatin-1 plazma seviyelerinin sağlıklı kişilerinkinden daha yüksek olduğu bulunmuştur $^{71}$.

Son veriler, NUCB2/nesfatin-1'in vücuttaki enerji durumu ile üreme arasındaki etkileşimde rol aldığını göstermektedir ${ }^{72,73}$. Özellikle dişilerin puberteye geçiş sürecinde, Nucb2 mRNA's1 ile protein ifadesinin hipotalamusta anlamlı seviyelerde arttığ $\operatorname{tir}^{45}$. Aksine, bu süreçte meydana gelen negatif bir enerji dengesi, hem Nucb2 mRNA'sını hem de protein ifadesini azaltmıştır ${ }^{45}$. Ayrıca, serbestçe beslenen pubertal dişi sıçanlara nesfatin-1'in merkezi enjeksiyonu luteinizan hormon ( $\mathrm{LH}$ ) sekresyonunu indüklerken, kısa süreli aç bırakılan dişi sıçanlarda bu sekresyonun daha fazla miktarda olduğu gösterilmiştir ${ }^{45}$.

Nesfatin-1'in erişkin hipotalamo-hipofizer gonadal (HPG) aksının düzenlenmesinde yer alıp almadığı bilgisi oldukça sınırlı olmasına karşın bir kaç ön veri bildirilmiştir. Erişkin dişi sıçanlara 50 pmol nesfatin1 'in i.c.v. enjeksiyonu plazmadaki LH düzeylerini etkilemezken ${ }^{45}$, nesfatin-1'in erkek sıçanlara çok yüksek dozda (1 nmol) verilmesi plazma LH ve FSH (folikül uyarıcı hormon) düzeyini arttırmıştır ${ }^{74,75} .2016$ yılında yapılan başka bir çalışmada ise, nesfatin-1'in i.c.v. enjeksiyonunun hipofizdeki FSH ve LH mRNA's1 ile hipotalamustaki GnRH mRNA ifadesini önemli ölçüde azalttığını göstermiştir. Bu sonuç, nesfatin-1'in HPG aksı üzerinde inhibe edici rol oynadığ1 şeklinde yorumlanmıştır ${ }^{76}$.

Nesfatin-1'in nöronal eksitabilitesini değiştiren bulgular, araştırmacıların bu peptidin epilepsi gibi nörolojik bozukluklardaki rolünü araştırmasına yol açmıştır. Primer epilepsi tanısı konan bireylerdeki tükürük ve serum nesfatin-1 düzeylerinin kontrolleriyle karşılaşt1rıldığında daha yüksek olduğu bulunmuştur ${ }^{77}$. Bu veriye ilave olarak sağlıklı bireylerle epileptik atak 


\section{D.G. Yurtseven, ark.}

geçiren hastaların serum nesfatin-1 düzeyleri karşılaştırıldığında atak geçiren hastaların serum düzeylerinin ataktan 48 saat sonrasında bile yüksek olduğu bulunmuştur $^{78}$. NUCB2/nesfatin-1'in epilepsi nöbetlerinin başlamasında tetikleyici mi yoksa engelleyici mi olduğu epilepsinin patofizyolojisini irdeleyen araştırmalardaki gelişmelerle netleşecektir.

REM uykusunun düzenlenmesi ile ilişkili olduğu bilinen tuberal hipotalamik alanda (THA) NUCB2/nesfatin-1'in melanin konsantre edici hormon (MCH) ile ko-lokalizasyonunun bulunması, araştırmac1lara NUCB2/nesfatin-1 proteini ile uyku arasında fonksiyonel bağlantıların olduğunu düşündürmüştür ${ }^{19}$. REM uykusunun bozulması, uyku ve uyanıklık döngüsünün regüle edildiği beyin bölgesi olan dorsal lateral hipotalamustaki Nucb2 mRNA's1 ile NUCB2/nesfatin-1 protein ifadesini azaltmıştır ${ }^{79}$. REM uykusunun yeniden geri gelmesi, NUCB2/nesfatin-1 nöronlarının aktive olmasını sağlamıştır ${ }^{80}$. Nesfatin-1'in i.c.v. enjeksiyonu sonrasında, REM uyku değişiklikleri üzerindeki azalma ${ }^{80}$ veya artışlar $^{81}$ bize NUCB2/nesfatin-1 proteini ile uyku arasında araştırılmayı bekleyen soruların olduğunu göstermektedir.

Besin alımının baskınlanmasında önemli etkisi olan nesfatin-1 peptidi ile ilgili literatürdeki çalışma sayıları hergün artmaktadır. Beslenme bozukluklarının anlaşılmasında ve bu bilgilerin ileride tedaviye yönelik kullanımında, nesfatin-1 peptidinin fizyolojisi, lokasyonu ve fonksiyonları açısından detaylı olarak araştırılması önem taşımaktadır.

\section{Teşekkür}

$\mathrm{Bu}$ derlemede yer alan laboratuvarımıza ait sonuçlar, TÜBİTAK tarafindan desteklenen $113 S 377$ nolu proje kapsamında yapılan çalışmalardan elde edilmiştir.

\section{Kaynaklar}

1. Oh-I S, Shimizu H, Satoh T. Identification of nesfatin-1 as a satiety molecule in the hypothalamus. Nature 2006;443:709-12.

2. Stengel A, Tache Y. Nesfatin-1-Role as possible new potent regulator of food intake. Regulatory Peptides 2010;163:18-23.

3. Stengel A, Goebel M, Wang L, Tache Y. Ghrelin, desacyl ghrelin and nesfatin-1 in gastric X/A-like cells: role as regulators of food intake and body weight. Peptides 2010;31:357-69.

4. Shimizu H, Ohsaki A, Oh-I S, Okada S, Mori M. A new anorexigenic protein, nesfatin-1. Peptides 2009;30:995-98.

5. Palasz A, Krzystanek M, Worthington J, et al. Nesfatin-1, a unique regulatory neuropeptide of the brain. Neuropeptides 2012;46:105-12.

6. Stengel A. Nesfatin-1-More than a food intake regulatory peptide. Peptides 2015;72:175-83.
7. Crespo CS, Cachero AP, Jimenez LP, Barrios V, Ferreiro EA. Peptides and food intake. Front Endocrinol (Lausanne) 2014;5:58-62.

8. Shimizu H, Oh-I S, Hashimoto K, et al. Peripheral administration of nesfatin-1 reduces food intake in mice: the leptinindependent mechanism. Endocrinology. 2009;150:662-71.

9. Garcia-Galiano D, Navarro VM, Gaytan F, Tena-Sempere M. Expanding roles of NUCB2/nesfatin-1 in neuroendocrine regulation. J Mol Endocrinol 2010;45:281-90.

10. Ishida E, Hashimoto K, Shimizu H, et al. Nesfatin-1 induces the phosphorylation levels of cAMP response element-binding protein for intracellular signaling in a neural cell line. PLoS One 2012;7:e50918.

11. Prinz P, Goebel-Stengel M, Teuffel P, et al. Peripheral and central localization of the nesfatin-1 receptor using autoradiography in rats. Biochem Biophys Res Commun 2016;470:521-27.

12. Dore R, Levata L, Lehnert H, Schulz C. Nesfatin-1: functions and physiology of a novel regulatory peptide. J Endocrinol 2017;232:R45-65

13. Nakata M, Manaka K, Yamamoto S, Mori M, Yada T. Nesfatin-1 enhances glucose-induced insulin secretion by promoting $\mathrm{Ca}(2+)$ influx through L-type channels in mouse islet beta-cells. Endocr J 2011;58:305-13.

14. Brailoiu GC, Dun SL, Brailoiu E, et al. Nesfatin-1: distribution and interaction with a $G$ protein-coupled receptor in the rat brain. Endocrinology 2007;148:5088-94.

15. Brailoiu GC, Deliu E, Tica AA, et al. Nesfatin-1 activates cardiac vagal neurons of nucleus ambiguus and elicits bradycardia in conscious rats. J Neurochem 2013;126:739-48.

16. Iwasaki Y, Nakabayashi H, Kakei M, et al. Nesfatin-1 evokes $\mathrm{Ca} 2+$ signaling in isolated vagal afferent neurons via $\mathrm{Ca}^{2+}$ influx through N-type channels. Biochem Biophys Res Commun 2009;390:958-62

17. Maejima Y, Sedbazar U, Suyama S, et al. Nesfatin-1-regulated oxytocinergic signaling in the paraventricular nucleus causesanorexia through a leptin-independent melanocortin pathway. Cell Metab 2009;10:355-65.

18. Foo KS, Brismar H, Broberger C. Distribution and neuropeptide coexistence of nucleobindin-2 mRNA/nesfatin-like immunoreactivity in the rat CNS. Neuroscience 2008;156: 563-79.

19. Fort P, Salvert D, Hanriot L, et al. The satiety molecule nesfatin-1 is co-expressed with melanin concentrating hormone in tuberal hypothalamic neurons of the rat. Neuroscience 2008;155:174-81

20. Goebel M, Stengel A, Wang L, Lambrecht NW, Tache Y, et al. Nesfatin-1 immunoreactivity in rat brain and spinal cord autonomic nuclei. Neurosci Lett 2009;452:241-46.

21. Inhoff T, Mönnikes H, Noetzel S, et al. Desacyl ghrelin inhibits the orexigenic effect of peripherally injected ghrelin in rats. Peptides 2008;29:2159-68.

22. Inhoff T, Stengel A, Peter L, et al. Novel insight in distribution of nesfatin-1 and phospho-mTOR in the arcuate nucleus of the hypothalamus of rats. Peptides 2010;31:257-62.

23. Kohno D, Nakata M, Maejima Y, et al. Nesfatin-1 neurons in paraventricular and supraoptic nuclei of the rat hypothalamus coexpress oxytocin and vasopressin and are activated by refeeding. Endocrinology 2008;149:1295-301.

24. Goebel-Stengel M, Wang L, Stengel A, Tache Y. Localization of nesfatin-1 neurons in the mouse brain and functional implication. Brain Res 2011;1396:20-34.

25. Maejima Y, Sedbazar U, Suyama S, et al. Nesfatin-1-regulated oxytocinergic signaling in the paraventricular nucleus causes anorexia through a leptin-independent melanocortin pathway. Cell Metab 2009;10:355-65.

26. Okere B, Xu L, Roubos EW, Sonetti D, Kozicz T. Restraint stress alters the secretory activity of neurons co-expressing urocortin-1, cocaine- and amphetamine-regulated transcript peptide 


\section{Anoreksijenik Peptit: Nesfatin-1}

and nesfatin-1 in the mouse Edinger-Westphal nucleus. Brain Res 2010;1317:92-9.

27. Feijoo-Bandin S, Rodriguez-Penas D, Garcia-Rua V, et al Nesfatin-1 in human and murine cardiomyocytes: synthesis, secretion and mobilization of Glut-4. Endocrinology 2013;154:4757-67.

28. Foo KS, Brauner H, Ostenson CG, Broberger C. Nucleobindin2/nesfatin in the endocrine pancreas: distribution and relationship to glycaemic state. J Endocrinol 2010;204:255-63.

29. Gonzalez R, Tiwari A, Unniappan S. Pancreatic beta cells colocalize insülin and pronesfatin immunoreactivity in rodents. Biochem Biophys Res Commun 2009;381:643-48.

30. Gonzalez R, Kerbel B, Chun A, Unniappan S. Molecular, cellular and physiological evidences for the anorexigenic actions of nesfatin-1 in goldfish. PLoS One 2010;5(12):e15201.

31. Ramanjaneya M, Chen J, Brown JE, et al. Identification of nesfatin-1 in human and murine adipose tissue: a novel depotspecific adipokine with increased levels in obesity. Endocrinology 2010;151:3169-80.

32. Stengel A, Goebel M, Yakubov I, et al. Identification and characterization of nesfatin-1 immunoreactivity in endocrine cell types of the rat gastric oxyntic mucosa. Endocrinology 2009;150:232-38.

33. Atsuchi K, Asakawa A, Ushikai M, et al. Centrally administered nesfatin-1 inhibits feeding behaviour and gastroduodenal motility in mice. Neuroreport 2010;21:1008-11.

34. Goebel M, Stengel A, Wang L, Tache Y. Central nesfatin-1 reduces the nocturnal food intake in mice by reducing meal size and increasing inter-meal intervals. Peptides 2011;32:36-43.

35. Chen X, Dong J, Jiang ZY. Nesfatin-1 influences the excitability of glucosensing neurons in the hypothalamic nuclei and in hibits the food intake. Regul Pept 2012;177:21-6.

36. Dong J, Guan HZ, Jiang ZY, Chen X. Nesfatin-1 influences the excitability of glucosensing neurons in the dorsal vagal complex and inhibits food intake. PLoS One 2014;9(6):e98967.

37. Moreau JM, Ciriello J. Nesfatin-1 induces Fos expression and elicits dipsogenic responses in subfornical organ. Behav Brain Res 2013;250:343-50.

38. Kerbel B, Unniappan S. Nesfatin-1 suppresses energy intake, co-localisesghrelin in the brain and gut, and alters ghrelin, cholecystokinin and orexin mRNA expression in goldfish. $\mathrm{J}$ Neuroendocrinol 2012;24:366-77.

39. Stengel A, Taché Y. Role of NUCB2/Nesfatin-1 in the hypothalamic control of energy homeostasis. Horm Metab Res 2013;45:975-79.

40. Konczol K, Pinter O, Ferenczi S, et al. Nesfatin-1 exerts longterm effect on food intake and body temperature. Int $\mathrm{J}$ Obes 2012;36:1514-21.

41. Stengel A, Goebel M, Wang L, et al. Central nesfatin-1 reduces dark-phase food intake and gastric emptying in rats: differential role of corticotropin-releasing factor2 receptor. Endocrinology 2009;150:4911-19.

42. Merali Z, Cayer C, Kent P, Anisman H. Nesfatin-1 increases anxiety- and fear-related behaviors in the rat. Psychopharmacology (Berl) 2008;201:115-123.

43. Chen X, Dong J, Jiang ZY. Nesfatin-1 influences the excitability of glucosensing neurons in the hypothalamic nuclei and inhibits the food intake. Regul Pept 2012;177:21-6.

44. Maejima Y, Sedbazar U, Suyama S, et al. Nesfatin-1-regulated oxytocinergic signaling in the paraventricular nucleus causes anorexia through a leptin independent melanocortin pathway. Cell Metab 2009;10:355-65.

45. Garcia-Galiano D, Navarro VM, Roa J, et al. The anorexigenic neuropeptide, nesfatin-1 is indispensable for normal puberty onset in the female rat. J Neurosci 2010;30:7783-92.
46. Sedbazar U, Maejima Y, Nakata M, Mori M, Yada T. Paraventricular NUCB2/nesfatin-1 rises in synchrony with feeding suppression during early light phase in rats. Biochem Biophys Res Commun 2013;434:434-38.

47. Mohan H, Unniappan S. Ontogenic pattern of nucleobindin2/nesfatin-1 expression in the gastroenteropancreatic tissues and serum of sprague dawley rats. Regul Pept 2012;175:61-9.

48. Zhang Z, Li L, Yang M. Increased plasma levels of nesfatin-1 in patients with newly diagnosed type 2 diabetes mellitus. Exp Clin Endocrinol Diabetes 2012;120:91-5.

49. Zhang AQ, Li XL, Jiang CY, et al. Expression of nesfatin1/NUCB2 in rodent digestive system. World J Gastroenterol 2010;16:1735-41.

50. Gonzalez R, Perry RL, Gao X, et al. Nutrient responsive nesfatin-1 regulates energy balance and induces glucose-stimulated insulin secretion in rats. Endocrinology 2011;152:3628-37.

51. Pan WH, Hung HC, Kastin AJ. Nesfatin-1 crosses the blood brain barrier without saturation. Peptides 2007;28:2223-8.

52. Price TO, Samson WK, Niehoff ML, Banks WA. Permeability of the blood-brain barrier to a novel satiety molecule nesfatin-1. Peptides 2007;28:2372-81.

53. Colmers WF. Less fat with nesfatin. Trends Endocrinol Metab 2007;18:131-32.

54. Wernecke K, Lamprecht I, Johren O, Lehnert H, Schulz C. Nesfatin-1 increases energy expenditure and reduces food intake in rats. Obesity 2014;22:1662-68.

55. Price CJ, Hoyda TD, Samson WK, Ferguson AV. Nesfatin-1 influences the excitability of paraventricular nucleus neurones. J Neuroendocrinol 2008;20:245-50.

56. Price CJ, Samson WK, Ferguson AV. Nesfatin-1 inhibits NPY neurons in the arcuate nucleus. Brain Res 2008;1230:99-106.

57. Gotoh K, Masaki T, Chiba S, et al. Nesfatin-1, corticotropinreleasing hormone, thyrotropin-releasing hormone, and neuronal histamine interact in the hypothalamus to regulate feeding behavior. J Neurochem 2013;124:90-99.

58. Noetzel S, Stengel A, Inhoff T, et al. CCK-8S activates c-Fos in a dose-dependent manner in nesfatin-1 immunoreactive neurons in the paraventricular nucleus of the hypothalamus and in the nucleus of the solitary tract of the brainstem. Regul Pept 2009;157:84-91.

59. Goebel M, Stengel A, Wang L, Tache Y. Restraint stress activates nesfatin-1-immunoreactive brain nuclei in rats. Brain Res 2009;1300:114-24.

60. Yosten GL, Samson WK. Nesfatin-1 exerts cardiovascular actions in brain: possible interaction with the central melanocortin system. Am J Physiol Regul Integr Comp Physiol 2009;297:R330-36.

61. Tanida M, Gotoh H, Yamamoto N, et al. Hypothalamic nesfatin-1 stimulates sympathetic nerve activity via hypothalamic ERK signaling. Diabetes 2015;64:3725-36.

62. Nakamura A, Johns EJ. Renal nerves, renin and angiotensinogen gene expression in spontaneously hypertensive rats. Hypertension 1995;25:581-86.

63. Tanida M, Mori M. Nesfatin-1 stimulates renal sympathetic nerve activity in rats. Neuroreport 2011;22:309-12.

64. Mimee A, Smith PM, Ferguson AV. Nesfatin-1 influences the excitability of neurons in the nucleus of the solitary tract and regulates cardiovascular function. Am J Physiol Regul Integr Comp Physiol 2012;302:R1297-1304.

65. Cone RD Anatomy and regulation of the central melanocortin system. Nat Neurosci 2005;8:571-78.

66. da Silva AA, do Carmo JM, Hall JE. Role of leptin and central nervous system melanocortins in obesity hypertension. Curr Opin Nephrol Hypertens 2013;22:135-40.

67. Yosten GL, Samson WK. Neural circuitry underlying the central hypertensive action of nesfatin-1: melanocortins, corti- 


\section{D.G. Yurtseven, ark.}

cotropin-releasing hormone, and oxytocin. Am J Physiol Regul Integr Comp Physiol 2014;306:R722-27.

68. Yoshida N, Maejima Y, Sedbazar U, et al. Stressor-responsive central nesfatin-1 activates corticotropin-releasing hormone, noradrenaline and serotonin neurons and evokes hypothalamicpituitary-adrenal axis. Aging 2010;2:775-84.

69. Xu YY, Ge JF, Qin G, et al. Acute, but not chronic, stress increased the plasma concentration and hypothalamic mRNA expression of NUCB2/nesfatin-1 in rats. Neuropeptides 2015;54:47-53.

70. Xu L, Bloem B, Gaszner B. Stress-related changes in the activity of cocaine- and amphetamine-regulated transcript and nesfatin neurons in the midbrain non-preganglionic Edinger-Westphal nucleus in the rat. Neuroscience 2010;170:478-88.

71. Ari M, Ozturk OH, Bez Y, Oktar S, Erduran D. High plasma nesfatin-1 level in patients with major depressive disorder. Prog NeuroPsychopharmacol Biol Psychiatry 2011;35:497-500.

72. Garcia-Galiano D, Tena-Sempere M. Emerging roles of NUCB2/nesfatin-1 in the metabolic control of reproduction. Curr Pharm Des 2013;19:6966-72.

73. Navarro VM, Kaiser UB. Metabolic influences on neuroendocrine regulation of reproduction. Curr Opin Endocrinol Diabetes Obes 2013;20:335-41.

74. Tadross JA, Patterson M, Wynne KJ, et al. Nesfatin suppresses feeding and stimulates the hypothalamo-pituitary-gonadal axis. 14th International Congress of Endocrinology 2010:S442.
75. Patterson M, Wynne K, Patel S, et al. Nesfatin stimulates the hypothalamic-pituitary-gonadal axis in male rats. Endocrine Abstracts 2011;25:P279.

76. Gao X, Zhang K, Song M, et al. Role of nesfatin-1 in the reproductive axis of male rat. Sci Rep 2016;6:32877.

77. Aydin S, Dag E, Ozkan Y, et al. Nesfatin-1 and ghrelin levels in serum and saliva of epileptic patients: hormonal changes can have a major effect on seizure disorders. Mol Cell Biochem 2009;328:49-56.

78. Aydin S, Dag E, Ozkan Y, et al. Time-dependent changes in the serum levels of prolactin, nesfatin-1 and ghrelin as a marker of epileptic attacks young male patients. Peptides 2011;32:127680.

79. Papp RS, Palkovits M. Brainstem projections of neurons located in various subdivisions of the dorsolateral hypothalamic area-an anterograde tract-tracing study. Front Neuroanat 2014;8:34.

80. Vas S, Adori C, Konczol K, et al. Nesfatin-1/NUCB2 as a potential new element of sleep regulation in rats. PLoS One 2013;8:e59809.

81. Jego S, Salvert D, Renouard L, et al. Tuberal hypothalamic neurons secreting the satiety molecule nesfatin- 1 are critically involved in paradoxical (REM) sleep homeostasis. PLoS One 2012;7:e52525. 